\title{
ACKNOWLEDGMENTS
}

In acknowledging those who have contributed to the development, execution, and writing of this research, it is unnatural for me to separate them into categories of "friends" or "colleagues," or some other designation; most if not all are both in various contexts and at different times. This work reflects over a decade of ethnographic and archaeological research among nomadic societies ranging from Sami reindeer herders in Finnish Lappland, Berber and Tuareg herdsmen in Tunisia, and of course, Kazakh mobile pastoralists of Kazakhstan and Xinjiang (China). Therefore, I would first like to thank the pastoralists: Hasan, Bolatai, Erlan, and many others, who opened their communities and lives to me and included me in the interactive arenas of their contemporary pastoralist landscapes. Without this experience, my understanding of Eurasian pastoralism would be deficit.

Throughout the growth of my research, a number of world-class scholars have encouraged and supported me. At the outset, I must acknowledge the immense role and contribution of Professors Ezra Zubrow and Renata Holod. Both represent formative figures in my professional development and have inspired me to pursue challenging intellectual problems. In addition, it is rewarding to offer this study to a community of scholars for whom I have great respect, gratitude, and who together form a dynamic community that drives research in the Eurasian steppe. Among others, I thank David and Dorcas Anthony, Claudia Chang, Perry Tourtellot, Sandra Olsen, Bryan Hanks, Phillip Kohl, Fredrick Hiebert, Karl Lamberg-Karlovsky, Colin Renfrew, William Honeychurch, Thomas Barfield and Adam Smith. These individuals have contributed variously 
to this research by sending me their most recent work, reading and reviewing chapters, and unselfishly discussing ideas with me.

This study developed substantially from my dissertation work at the University of Pennsylvania, where a number of individuals (in addition to those named above) played a role its development. I am grateful to Gregory Possehl, Victor Mair, Clark Erickson, Holly Pittman, Naomi Miller, Robert Dyson, and Bernard Wailes for their interest in and guidance of my research at Penn. I am also grateful for the financial support provided by the Louis J. Kolb Society at Penn, the George F. Dales foundation, and the American Councils for International Education. Without these contributions, I would not have managed to spend so much time in Kazakhstan or have been afforded the requisite time to explore the wide array of topics and languages this study demanded.

In Kazakhstan, I am indebted to Dr. Alexei Mar'yashev, Yuri Peshkov, and Alexei Rogozhinski, who were instrumental to my archaeological and ethnographic field experiences. Without them, my knowledge of the archaeology and language of Kazakhstan would not have developed . I also would like to thank Professor Karl Baipakov, the director of the Institute of Archaeology in Almaty, for his support in making my research there a reality and for developing international relationships in Central Asian archaeology. In fact, everyone at the institute in Almaty played an important role in making this research a success, and I am grateful to them. Also in Kazakhstan, I would like to acknowledge Bulat Aubekerov and Saida Nigmatova at the Institute of Geology for their collaborative work concerning paleobotany and geology and for their key roles in the planning and execution of stages of the fieldwork. My field research in Kazakhstan was supported by two grants from the National Science Foundation (\#02II43I and \#053534I).

I would also like to thank a number of European scholars, whose research expands the breadth of Eurasian archaeology, and from whom I have benefited greatly. I first thank Professor Elena Kuz'mina. Her corpus of research on Eurasian archaeology is astonishing and worthy of admiration. While researching this book, I had the opportunity to visit and talk with Professor Kuz'mina in Moscow. She invited me to dinner at her home, which contains an amazing library of Bronze Age Eurasian archaeology. From our conversations, I understood that although I am presenting an alternative view of the evolution of Bronze Age steppe societies, my approach is possible only because of the comprehensive work conducted by scholars like Kuz'mina and her contemporaries. I can only aspire to one day have such an impact on future generations of scholars. I would also like to thank Natalia Shishlina for her guidance in Moscow and for introducing me to Russian theatre and culture there. In Ukraine, I would like to thank Yuri Rassamakin, Yuri Boltrik, and others at the Institute of Archaeology in Kiev. This study also benefited from a nine-month research stay at the Eurasian department of the German Archaeological Institute in Berlin. I would like to acknowledge the director Professor Hermann Parzinger, as well as Sven Hansen, Nicholas Borofka, and Norbert Benecke for their help and contributions to my work there. I am also grateful to Elizabeth 
Fentress for lengthy conversations about composition and content, and for offering the most wonderful setting in Italy where I drafted a number of chapters.

Large portions of this book were written at Washington University in St. Louis, where I have benefited greatly from the contributions of my colleagues in the Department of Anthropology. First, I would like to thank Professor Lois Beck, who read drafts of this manuscript at various stages and contributed to its organization. In addition, I thank Professors Fiona Marshall and David Browman for inviting me to participate in a seminar concerning world nomadism in 2006 . In the course of the semester, our fruitful discussions of nomadic landscapes beyond Eurasia further informed my ideas in the final stages of writing this book. I must also acknowledge my students: Taylor Hermes, Brandy Trimble, Dan Kandy, Nicholas Efremov-Kendall, Robert Spengler, Lynne MuroneDunn, and Paula Doumani, who were very helpful in the editing of this manuscript. Finally, I must thank Dr. Sarah Rivett, who was a supportive sounding board for ideas and issues as they arose throughout the writing of this book. Her role as a primary reader of chapters as they came out was fundamental to the organization and shape of this work.

Finally, I would like to thank my family and parents, to whom I dedicate this book. You remind me that no matter the expanse of your mental map, there is continuity at the heart of it.

\section{NOTES ON TRANSLATION}

All non-English quotations cited throughout the text were translated from the source language by the author, unless otherwise noted. Where a quotation is from a work that is itself a translation of the original into a language other than English, the language of the mediating source is noted. All Russian placenames, proper names, and toponyms have been transliterated using the BGN/PCGN 1947 romanization of Russian. Dates are presented in calibrated years before the Current Era (BCE) or Current Era (CE), unless otherwise indicated. 
